\title{
A Revitalização Urbana Contributos para a Definição de um Conceito Operativo ${ }^{1}$
}

\author{
Dulce Moura* $^{*}$ Isabel Guerra ${ }^{* *}$, João Seixas ${ }^{* * *}$ e Maria João Freitas ${ }^{* * * *}$
}

\begin{abstract}
$\mathrm{R}_{\mathrm{e}}$ reflexão para formulação estratégica e operacional das actuacões a concretizar no QREN, de Outubro de 2005 - que pretendia apontar conteúdos e formas de desenho de um potencial programa em revitalização urbana inserido no próximo quadro comunitário.

Dada a mutação das sociedades, a diversidade de situações a considerar e a proliferação de conceitos, a primeira preocupação foi a de situar o conceito de revitalização urbana no contexto da diversidade de conceitos da mesma família: requalificação, reabilitação, renovação, etc. Assentando num conceito englobante que define a revitalização urbana como um processo integrado de reanimação de parte da cidade e onde se podem incluir operações de vária ordem, pretende-se depois estruturar uma tipologia de situações empíricas que permitam dar corpo à diversidade potencial de intervenções em nome da referida revitalização urbana.
\end{abstract}

Palavras-chave: Revitalização; Renovação urbana; Requalificação; Reabilitação.

\section{Introdução}

No relatório Políticas Públicas de Revitalização: reflexão para formulação estratégica e operacional das actuaçōes a concretizar no QREN, propõe-se que o conceito de Revitalização Urbana seja entendido sobretudo como uma estratégia e um processo, distinguindo-se da generalidade dos programas urbanísticos, de um modo geral sem transversalidade e integração nas suas linhas de actuação. Neste sentido, a revitalização urbana desenvolve estratégias e promove um processo com carácter inclusivo e integrador, capaz de provocar iniciativas, projectos e actuações - de carácter transversal e sectorial, sendo um instrumento de gestão colectiva do território com capacidade para utilizar, como recursos próprios, programas urbanos muito diferenciados, de cariz mais social, económico ou cultural.

Propõe-se ainda uma tipologia de territórios a revitalizar com base na situação actual do território português: Centros urbanos e núcleos históricos, Expansões periféricas ou peri-urbanas, Áreas de oportunidade pontual ou estratégica, Espaços de reserva com potencialidade derivada, Espaços de relação e sinergia.

\section{Uma proposta de clarificação conceptual em torno da revitalização urbana}

O pós-guerra 1945-1975 desenvolveu-se como o período que antecedeu a concepção da revitalização urbana, tal como hoje a conhecemos. De facto, a maioria dos países ocidentais, nestes "30 anos gloriosos", desenvolveram um modelo económico de estruturação dos Estados Providência, onde as políticas sociais do Estado, nomeadamente as ligadas à construção, edificaram uma reconstrução económica e social, à qual as cidades também não escaparam, vivendo um intenso crescimento económico de matriz fordista.

\footnotetext{
Este artigo é parte do relatório Políticas Públicas de Revitalização: reflexão para formulação estratégica e operacional das actuaçōes a concretizar no QREN, Outubro de 2005 onde participaram vários peritos.

* Socióloga, investigadora do CET e perita em SECOT.

** Professora do Departamento de Sociologia do ISCTE, investigadora do CET.

*** Professor na Universidade de Barcelona, investigador do CET.

**** Investigadora do LNEC e administradora no INH.
} 
As necessidades de renovação e revitalização das cidades colocaram-se com mais insistência no último quartel do século xx, com o envelhecimento de zonas de construção massiva no pós-guerra ou com o declínio das velhas zonas industriais e portuárias características das fases de industrialização pesada. Apesar de no contexto europeu as experiências de intervenção em zonas degradas ou em degradação e as "políticas" que as suportaram terem sido inúmeras e diferenciadas, desenvolve-se hoje um largo consenso sobre alguns dos princípios orientadores dessas políticas.

Programas como o "Neighbourhood Renewal Strategy" em Inglaterra nascem ainda da tradição de compromisso social do Estado junto das populações desfavorecidas das grandes cidades remontando aos movimentos reformistas urbanos do início do século xx, passando posteriormente pela racionalização das medidas de ajuda à regeneração ("Single Regeneration Budget Programme", 1994), até à fase actual, quando, em 1997, a chegada ao poder do New Labour levou à criação de uma unidade dedicada à exclusão social ("Social Exclusion Unit") que procura dinamizar a reflexão estratégica sobre a revitalização nos bairros urbanos mais desfavorecidos.

$\mathrm{O}$ primeiro governo de Margaret Thatcher, em 1979 na Grã-Bretanha, é o ponto de partida para este novo cenário de tipo neoconservador enquanto governo do estado e neoliberal na gestão do território. A política urbana e territorial passou a ser algo negociado e negociável entre o sector público e os agentes privados, entre a procura de uma economia global e as exigências do território local.

As instâncias públicas adoptaram um papel de subsidiariedade, desde facilidades fiscais ou flexibilidade no planeamento, até à eventual participação activa no comércio especulativo do solo afectando, inclusive, as propriedades públicas (ex. as Docklands em Londres, ou a companhia ferroviária estadual de Berlim reunificada, propriedades públicas que foram postas ao serviço de estratégias privadas altamente especulativas).

$\mathrm{O}$ que caracterizou a intervenção urbana thatcheriana foi, por um lado, a primazia à reabilitação física com o claro objectivo de "devolver à cidade" solos com forte valor fundiário e, por outro lado, a promoção da competição entre municípios para o acesso aos fundos de investimento imobi- liário juntamente com uma forte "privatização" da intervenção na regeneração urbana.

Entretanto, a economia internacional evoluiu para um modelo de economia global onde as cidades e as regiões urbanas foram fortemente influenciadas. Novos conceitos como a flexibilidade ou a desregulação têm de se articular neste novo período com as questões urbanas, ao nível das repercussões:

- nas mutações económicas: fragilização do modelo fordista, emergência de novas formas de relação com o trabalho e precarização dos percursos individuais, desconexão entre o económico e os territórios, predominância de um regime internacional com hegemonia do capital financeiro, mobilidade de capitais e desconexão progressiva entre território de produção de riqueza e território do consumo;

- nas mutações sociais: fragilização e fragmentação da família, aumento das desigualdades de mercado, diversificação crescente das trajectórias individuais, envelhecimento da população, aumento das mobilidades populacionais.

Em França, entre a lei Malraux de 1962, que marca o início da preocupação pública francesa em preservar o habitat no centro das cidades francesas e as consequentes fases da "Politique de la Ville", até à recente lei da "Solidarité et Renouvellement Urbains", que pretende revitalizar os "quartier en crise", desenvolveram-se muitos debates e transformações sobre o modo de pensar e fazer a própria revitalização (reabilitação, requalificação...). Pelos vários documentos que acompanharam este debate, constata-se que não houve propriamente uma ruptura, mas que as problemáticas e os métodos de intervenção se foram enriquecendo com as experiências de terreno.

Assim, aos princípios estabelecidos nos anos 70, nas primeiras “Opérations Programmées d'Amélioration de l'Habitat", acrescentaram-se os benefícios das operações de "Développement Social des Quartiers" orientadas para as periferias, onde se concentravam os bairros sociais de construção massiva da geração anterior. A montagem de equipas pluridisciplinares, um trabalho mais integrado e uma inovação nos estaleiros de 
construção, estruturaram uma política pública onde os princípios da experimentação e da avaliação foram sempre suportados por um Estado forte e interventor ${ }^{2}$.

Nos modelos de fragilização dos Estados Providência - liberais, socio-democráticos ou corporativistas-conservadores -, desenvolveram-se as novas premissas que coincidiram com uma maior liberalização por parte do Estado e das instâncias públicas na actividade económica e empresarial. E este período levou a alguns cenários territoriais recorrentes:

- a diminuição do controlo do território por parte das instâncias públicas com pressões fundiárias e imobiliárias por parte do sector empresarial;

- a progressiva "privatização" da lógica urbana nomeadamente de alguns serviços tradicionalmente de responsabilidade pública, processo aliás muito evidente ao nível das mobilidades e comunicações e que está ainda hoje em curso;

- a especialização de territórios em monocultivos urbanos, como o turismo, ou os usos vinculados ao entretenimento urbano, e o desenvolvimento de problemas e sectores urbanos que deixam de ter resposta eficaz (ex. habitação social nas grandes cidades);

- aumento da competitividade territorial entre municípios e regiões vizinhas;

- a distribuição territorial desigual do investimento, dirigida a sufragar projectos ambiciosos de grandes firmas ou nomes da arquitectura, para crescimento e transformação das áreas urbanas (cada espaço quer ter arquitectos - marca e edifícios - logo singulares para se inserir no mapa global das imagens urbanas); ou

- o aumento da polarização territorial através da pauperização de territórios pouco apetecíveis ou em perda de valor por razões várias.

Do ponto de vista dos processos, no final do século $\mathrm{xx}$, as políticas territoriais não ficaram à margem da tendência generalizada do aumento da competitividade, da procura da inovação e da mercantilização dos valores fundiários e imobiliários, pelo que foram definidas em termos de:

1) desenvolvimento da planificação estratégica, enquanto articulação entre agentes públicos e privados;

2) multiplicação das parcerias e equipas de gestão com a colaboração público-privado, como meio de agilizar e flexibilizar a gestão das questões territoriais;

3) desenvolvimento de políticas de marketing e promoção territorial aumentando a competitividade entre cidades no conceito de um mercado global;

4) privatização, selectiva e algumas vezes indiscriminada, de infra-estruturas e serviços que eram públicos (higiene, transportes...).

Mas a emergência do mercado globalizado, do novo capitalismo neoliberal (que vem procurar a acessibilidade e o simbolismo das áreas centrais, contrariando as descontinuidades e os limites internos ao crescimento e à expansão da economia), surge simultaneamente à propagação do paradigma do desenvolvimento sustentável e à consolidação dos movimentos comunitários e ambientalistas.

As experiências do final do século xx permitem definir a revitalização no contexto do planeamento estratégico das cidades e territórios, como forma de contrariar o urban decline, processo de deterioração e declínio das áreas centrais ou marginalizadas, mantendo a cidade em constante renovação e procura de factores de inovação.

\section{Conceitos e realidades que concorrem para a revitalização urbana}

Ao longo do tempo, a desactualização de zonas da cidade - central ou periférica - chamaram a atenção pela necessidade de lhes dar novas funções. Frequentemente, a oportunidade gerada pelo envelhecimento de alguns dos equipamentos e bens urbanos aí localizados chamam a atenção para possíveis valorizações dos sítios em termos imobiliários, culturais e sociais. A lógica de intervenção urbana nesses espaços muda no

\footnotetext{
${ }^{2}$ Ver uma síntese das experiências francesas em reabilitação em http://www.urbanisme.equipement.gouv.fr/cdu/accueil/bibliographies/ rehabilitation/preface.htm
} 
tempo mas também opõe ideologias face à cidade, nem sempre reconciliáveis, dada a diversidade e interesses. Surgem, assim, conceitos que, embora nem todos bem definidos, contêm simultaneamente uma ideia (teórica) e uma proposta de acção sobre a cidade. É o caso dos conceitos de renovação urbana, reabilitação, requalificação.

\section{Renovação urbana}

O conceito da renovação urbana é marcado pela ideia de demolição do edificado e consequente substituição por construção nova, geralmente com características morfológicas e tipológicas diferentes, e/ou com novas actividades económicas adaptadas ao processo de mudança urbana. Os efeitos sociais que esta política teve onde foi aplicada são conhecidos dos estudos urbanos e, nos casos de cidades norte-americanas e francesas, implicou:

- a reocupação das zonas centrais pelas actividades económicas de ponta (escritórios de grandes empresas multinacionais, sector financeiro);

- e a expulsão de parte da função residencial dos centros das cidades com a progressiva periferização das classes médias, ou ainda das actividades económicas de fraca capacidade económica para competir no mercado imobiliário com as empresas de elevado estatuto económico e grande prestígio que buscavam no centro uma localização estratégica.

Em Portugal, este tipo de intervenção foi aplicado extensivamente na época do Estado Novo (lembre-se o caso do Martim Moniz, da Alta de Coimbra, o projecto do Auzelle para a Ribeira Barredo no Porto, etc.) pois, ao mesmo tempo que se proclamava o restauro dos monumentos, procedia-se ao nível do planeamento, sob pretextos higienistas ou de necessidade viária, a uma substituição dos tecidos antigos. Nesse contexto, o tecido antigo é considerado caduco, insalubre, sem valor patrimonial e impeditivo da modernização, propondo-se a sua demolição ou renovação. Nos planos de urbanização, os tecidos antigos passam a ser preservados em "formol" - processo de folclorização e institucionalização do património - ou esventrados para dar visibilidade aos monumentos, instalar instituições de âmbito nacional com imagem de reforço dos valores e poder do Estado, "limpar" tecidos "insalubres" socialmente e urbanisticamente, ou reorganizar a rede viária.

A ideia de renovação atinge, sobretudo, as intervenções de larga escala, de transformação integral. Implica, por isso, uma mudança estrutural que abrange 3 dimensões básicas:

- dimensão morfológica (forma da cidade e da paisagem);

- dimensão funcional (base económica e das funções a ela associadas que podem desaparecer ou ser substituídas)

- dimensão social (esfera sociológica, geralmente substituição de residentes ou visitantes por outros com níveis de rendimento, instrução e estilo de vida diferentes).

Estas operações têm um carácter zonal destacado e tornam-se geralmente 'áreas de renovação' ou 'sectores de renovação' (como a City londrina nos anos 80; a renovação de Berlim reunificado no início dos anos 90 ou a frente marítima de Barcelona desde os anos 80).

\section{Reabilitação}

A renovação faz um tratamento hard do tecido edificado e, por consequência, do tecido social e económico. A reabilitação não representa a destruição do tecido, mas a sua "habilitação", a readaptação a novas situações em termos de funcionalidade urbana. Trata-se de readequar o tecido urbano degradado, dando ênfase ao seu carácter residencial, no qual geralmente se fazem duas intervenções complementares:

- no edificado (habitabilidade, qualidade da habitação, serviços e instalações, e isolamento térmico e acústico), implicando não somente a reabilitação dos edifícios habitacionais, como a dos outros edifícios, incluindo mesmo a construção de equipamentos. Além disso, a reabilitação urbana não implica uma intervenção igual em todos os edifícios, podendo implicar a demolição de alguns, o restauro estrito de outros, a construção de novos, etc., do mesmo modo que reabilitar um edifício pode implicar a demolição de alguns elementos e a construção de novos; 
- na paisagem urbana (elementos de visibilidade, fachadas, espaços de transição como o espaço público contíguo ao residencial), na medida em que as intervenções de reabilitação surgem muitas vezes associadas a actuações de melhoramento do espaço público ou revitalização do mesmo.

É dado especial cuidado no "processo" de reabilitação, metodologias, equipas, parcerias e participação. Este processo pode facilitar algumas etapas complexas da reabilitação, como o realojamento provisório das populações residentes ou os acordos com os proprietários. Em finais dos anos 80, desenvolve-se a ideia, de um modo mais consistente, da reabilitação urbana em Portugal (com uma diferença de mais de uma década em relação à Europa), pese embora experiências pontuais desencadeadas em meados dos anos setenta, na zona ribeirinha do Porto, por exemplo.

Preocupações com o património histórico-arquitectónico e com a manutenção da população nos centros das cidades comandam esta nova política de intervenção urbanística (Ribeira-Barredo no Porto, Évora, Guimarães, ou mesmo em Lisboa).

A criação de gabinetes técnicos locais em Portugal (foram lançados os primeiros 37 GTLs em 1985, simultaneamente, de Norte a Sul do país) deu um importante contributo para o desencadear de operações planeadas de intervenção no espaço construído, de natureza histórico-patrimonial. $\mathrm{O}$ que faltou, muitas vezes, foi um investimento continuado nessas experiências de reabilitação, a sua avaliação e, sobretudo, o balanço da sustentabilidade das intervenções e o seu contributo efectivo para o desenvolvimento urbano, ou desenvolvimento local, dos contextos onde ocorreram.

A maioria daquelas intervenções em Portugal acabou por ter um peso quase exclusivo da dimensão física da reabilitação, dissociada de intervenções no tecido económico e social dos contextos de intervenção. Mesmo quando tais intervenções ocorreram, elas pautaram-se mais pela lógica de reabilitar o que existe e, tal como se procedia face ao edificado (onde a preservação e habilitação do tecido urbano e do edificado é um objectivo bastante mais prioritário que o da ino- vação), muitas vezes a estratégia era evitar que a operação de reabilitação física acarretasse processos de expulsão dos habitantes e substituição destes por outras camadas sociais: "a reabilitação significa a restituição da estima pública. Sendo o seu objectivo criar condições para que as pessoas não só possam viver e sobreviver em condições consideradas adequadas, mas, também, criar condições de maneira a que estes núcleos ou essas cidades constituam núcleos estimados pela sociedade e a colectividade." (Arq. ${ }^{\circ}$ Alcino Soutinho in $2 .^{\circ}$ Encontro dos Programas Urban e Reabilitação Urbana, 1998:48).

$\mathrm{O}$ procedimento de reabilitar que existe, que a maioria dos $\mathrm{GTL}^{3}$ assumiu claramente como um objectivo de actuação, deve-se ao facto de eles terem operado sempre em áreas de elevado valor histórico e patrimonial. De facto, apesar de após 1987 haver a possibilidade de os GTLs operarem em áreas urbanas degradadas "não-históricas", na realidade isso não veio a acontecer, porque na selecção das candidaturas (e como os recursos eram escassos) deu-se sempre a preferência às áreas antigas por serem consideradas prioritárias relativamente a outras. Por outro lado, a partir dos anos noventa, houve directrizes fortes para que a actuação dos GTLs se centrasse na elaboração de Planos de Salvaguarda e não em operações concretas.

No que se refere ao ambiente construído, em 1998 a CE adoptou a comunicação "Desenvolvimento Urbano Sustentável na União Europeia: um Quadro de Acção", onde aponta a reabilitação das áreas urbanas degradadas e a melhoria da qualidade do ambiente construído como objectivos a atingir pela União Europeia. Este documento sublinha a necessidade das acções de reabilitação urbana serem realizadas de forma integrada e de se tornarem numa componente essencial das políticas locais de planeamento. Em 2001, a Resolução do Concelho da União Europeia "Sobre a qualidade arquitectónica em ambientes rurais e urbanos" dá indicações no sentido de que a dimensão cultural e a qualidade do tratamento físico do espaço sejam tidas em conta nas políticas europeias de coesão, e sublinha a importância de defender o elemento cultural e patrimonial.

\footnotetext{
${ }^{3}$ Gabinetes Técnicos Locais organizados pelas Câmaras Municipais em zonas históricas a reabilitar.
} 
$\mathrm{Na}$ comunicação da CE “Desenvolvimento urbano sustentável na União Europeia: Um quadro de acção", o desenvolvimento cultural e o património são apontados como factores cruciais para a vitalidade das cidades e para o seu desempenho económico. A reabilitação dos núcleos urbanos históricos é hoje assumida como um dos pilares na economia de usos e ocupações do solo, na rentabilização do espaço construído e na dotação de bens de utilidade pública - equipamentos e infra-estruturas. Por outro lado, a reabilitação urbana é uma actividade geradora de emprego nas áreas da conservação e turismo e uma fonte de receita para as cidades que se tornam destinos mais atractivos.

Nas conclusões finais da Conferência Intergovernamental "Cultural Policies for Development: The Power of Culture" (1998), assim como na resolução anteriormente referida "Sobre a qualidade arquitectónica em ambientes rurais e urbanos", defende-se que a diversidade cultural permite uma melhor qualidade de vida. Assim, como forma de contrariar os efeitos negativos da globalização, são vitais os esforços no sentido de reforçar a autenticidade e a diversidade cultural, preservando e valorizando o património construído. A imagem da cidade, e dos centros históricos em particular, é um factor fundamental para o reforço dos laços identitários da população e para a coesão social. A reabilitação integrada dos tecidos históricos emerge como uma via privilegiada de atingir estes objectivos, agindo de forma concertada sob os aspectos físicos, culturais, sociais e funcionais do tecido urbano.

Em 1992, o Quinto Programa da Comunidade Europeia (CE) de Política e Acção em Matéria de Ambiente e Desenvolvimento Sustentável, sublinha a necessidade de estudar o desenvolvimento sustentável como uma prioridade, particularmente no que diz respeito às necessidades da urbanização em conflito com a conservação dos recursos e protecção ambiental. Na complexa interacção das diferentes forças e pressões que dão origem aos problemas ambientais, o papel do ordenamento e gestão do território é apontado como crucial. Em 2001, o Sexto Programa de Acção em Matéria do Ambiente da CE refere explicitamente que para que a expansão urbana não se faça às expensas do ambiente, deve ser promovida a reabilitação urbana em oposição à construção em locais novos. Para uma política de desenvolvimento sustentável, que assegure o nosso bem-estar a longo prazo e defenda o património que deixamos às gerações futuras, a reabilitação dos núcleos históricos assume uma grande importância. $\mathrm{O}$ património edificado é, em si próprio, um recurso finito e insubstituível e a sua destruição é um dano irreversível. Por outro lado, a crescente perda de solos em favor da urbanização justifica a necessidade de uma abordagem sistemática à protecção e racionalização do uso dos solos, sendo a reabilitação dos tecidos construídos uma alternativa à urbanização extensiva e ao consumo desnecessário de recursos não renováveis. Por último, a demolição de edifícios existentes levanta problemas de ordem ecológica, como o tratamento dos resíduos sólidos e o dispêndio de mais recursos para a construção de novos edifícios.

\section{Requalificação}

A requalificação urbana é sobretudo um instrumento para a melhoria das condições de vida das populações, promovendo a construção e recuperação de equipamentos e infra-estruturas e a valorização do espaço público com medidas de dinamização social e económica. Procura a (re)introdução de qualidades urbanas, de acessibilidade ou centralidade a uma determinada área (sendo frequentemente apelidada de uma política de centralidade urbana).

Provoca a mudança do valor da área, ao nível económico (actividades económicas com alto valor financeiro), cultural (localização de usos económicos relacionados com a cultura), paisagístico e social (produção de espaços públicos com valor de centralidade).

A requalificação urbana tem um carácter mobilizador, acelerador e estratégico, e está principalmente voltada para o estabelecimento de novos padrões de organização e utilização dos territórios, e para um melhor desempenho económico (ex. as experiências de reintrodução de actividades logísticas e terciárias em Ranstaad/ Holanda; a Área da Nova Centralidade de Barcelona, antes e depois dos Jogos Olímpicos; Bilbao, Londres ou Newcastle).

\section{Promoção urbana}

Esta é uma faceta com pouca visibilidade quando integrada em processos de revitalização, e consiste: 
- na atracção de esforços de todo o tipo económicos, institucionais e sociais; - quando se vai iniciar uma operação de revitalização (marketing do programa e consolidação dos pressupostos económicos), etc;

- na comunicação de todos os progressos da operação de revitalização urbana e criação de consensos em torno da sua evolução futura, que é uma condição sine qua non de todo o processo de revitalização - é tão importante concretizar objectivos, como dar-lhes visibilidade na colectividade e fazer a colectividade participar deles ("governança", base de um processo de gestão urbana e territorial).

As políticas de promoção urbana estão na retaguarda da gestão e da comunicação do processo de revitalização e cobrem actuações como o fund-rising, o marketing, e o novo branding urbano e territorial.

Face à implementação de muitos programas desenvolvidos nas últimas décadas centrados na promoção dos centros históricos e áreas com uma "herança" turístico-cultural, as experiências mais interessantes giraram em torno de uma carta de apresentação que sintetiza os objectivos da revitalização (ex. estratégias de promoção do enoturismo em França e Espanha).

\section{Revitalização urbana: um conceito englobante}

Sem uma grande preocupação de destrinça, interessava delimitar o "mercado das ideias" para a intervenção, ou os principais consensos sobre os conceitos aparentados, o que nos permitiu, por um lado, distanciarmo-nos deles e, por outro lado, redefinir o nosso próprio posicionamento. Todos os conceitos atrás apresentados e a sua operacionalidade enquanto Programas e Projectos, podem integrar-se numa intervenção mais vasta de revitalização urbana.

É neste contexto conceptual, ou de diferentes modelos de intervenção (nem sempre claramente distintos, raramente indissociáveis na intervenção face a um território), que se discutem as principais tendências no que se refere às políticas urbanas e territoriais relacionadas com a revitalização nos últimos 20 anos. As experiências de intervenção territorial realizadas ao longo de 5 décadas, de responsabilidade nacional ou comunitária, colocaram em cima da mesa, em todos os países europeus, alguns dos princípios base a que devem obedecer os programas de revitalização. As experiências realizadas questionam o conteúdo (demasiado físico) das operações, mas também as formas de gestão: processos burocratizados, sem participação pública e frequentemente conflituais.

A palavra de ordem é integrar: integrar dimensões de intervenção; integrar funções urbanas; integrar parceiros e recursos. Nesse contexto, a revitalização assenta na implementação de um processo de planeamento estratégico, capaz de reconhecer, manter e introduzir valores de forma cumulativa e sinergética. Isto é, intervém a médio e longo prazo, de forma relacional, assumindo e promovendo os vínculos entre territórios, actividades e pessoas. Não é, portanto, um projecto, ou uma soma de vários projectos ou de programas introduzidos num dado território, procurando-se antes garantir uma operação sustentável, a níveis diferenciados, mas em interdependência no desenho da intervenção ou na sua implementação, como:

1. a performance económica e financeira ("economic viability");

2. a sustentabilidade física e ambiental ("environmental responsibility"); e

3. a coesão social e cultural ("social and cultural equity").

Assim, a revitalização urbana obriga a intervir na melhoria da qualidade do ambiente urbano, das condições socioeconómicas ou no quadro de vida de um determinado território ('território de revitalização urbana'), baseando-se numa visão global, actuando de forma integrada e concertando um grande número de domínios e dimensões de intervenção. A sua actuação não é rígida, mas adapta-se às realidades territoriais, nas quais intervém pretendendo coordenar e adaptar os recursos existentes e potenciais, públicos e privados, apelando à população e às entidades que as representam para serem co-autoras do processo de revitalização.

Como se desenvolverá adiante, a consideração dos territórios de revitalização urbana deve ainda integrar duas dimensões fundamentais: a lógica do lugar mas também a sua inserção numa 


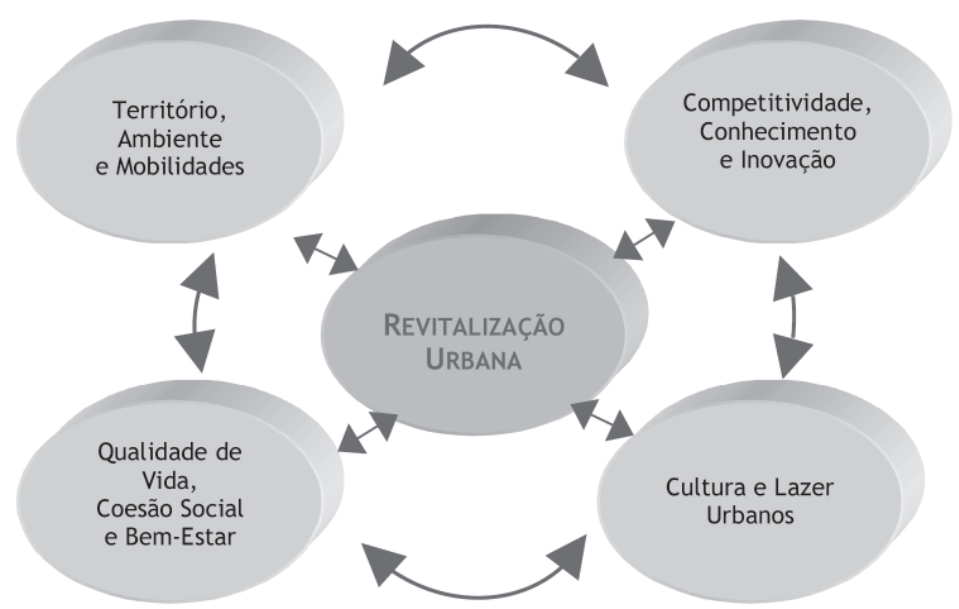

Figura 1 - Dimensões de Intervenção da Revitalização Urbana

perspectiva sistémica do sistema territorial de onde recolhe a sua lógica própria e a sua identidade específica.

A lógica sistémica privilegia a cooperação entre diferentes escalas e territórios (área envolvente, cidade, região, sistema nacional), compreendendo o papel que a "área a revitalizar" desempenha no sistema urbano, sublinhando os efeitos indutores na sua área de influência (significa perceber tanto os resultados no lugar, como os impactos territoriais alargados). A lógica do lugar sublinha a intervenção enquanto actuação de proximidade, reforçando a mobilização e a participação dos diferentes actores de um espaço fisicamente delimitado, numa lógica de acção concertada. Um olhar sistémico e integrado sobre a revitalização urbana exige a sua discussão, quer numa perspectiva mais vasta e integrada de Política das Cidades e Formas de Governação Urbana quer, ainda, no contexto empírico da estrutura de ordenamento e administração do território nacional.

O processo de revitalização desenvolve-se, a médio e longo prazo, numa perspectiva de sustentabilidade da intervenção, articulando as oportunidades, as vantagens competitivas e um urbano cada vez mais globalizado, de expressão localizada. Baseia-se, sobretudo, nos “opportunity projects", na colaboração privado/público (investidores) e na relação com as comunidades. As operações de revitalização tendem ainda a intervir a montante dos factores de desvitalização, ou de outros potencialmente vitais, de modo a promover uma intervenção sustentável.
A revitalização urbana, enquanto processo de trazer "nova vida" ou trazer "de novo" dinâmicas perdidas, desenvolve uma perspectiva claramente organicista e vitalista, na análise e no modo de planeamento do processo de urbanização ou do território urbanizado. Mas, antes de mais, trata-se de um conceito complexo e as estratégias, as metodologias e os instrumentos de revitalização podem abranger muitas vertentes, desenvolvidas por outros modelos de intervenção na transformação do espaço urbano.

A leitura das diferentes propostas de definição do conceito, partindo de autores e experiências de intervenção urbana, permite-nos extrair alguns critérios de diferenciação. Assim, entre as propostas analisadas, encontramos:

1. Em primeiro lugar, apesar do conceito de revitalização pressupor uma abordagem meramente negativa (reactiva), colocando em evidência as situações e/ou os factores de desvitalização, é sobretudo uma abordagem positiva (pró-activa) tendo em consideração os factores potenciadores de novos dinamismos;

2. Em segundo lugar, os entendimentos da revitalização enfatizam quer um maior centramento nos indivíduos e no enquadramento social e cultural, quer nas dimensões físicas do edificado e das formas urbanas;

3. Em terceiro lugar, emerge a distinção entre as definições mais descritivas e funcionais que recenseiam aquilo que está contido no conceito (valores urbanos, defesa de certas formas de edificado e organização urbana, objectivos estraté- 
gicos; etc.) e as definições mais processuais que enfatizam as dimensões activas das formas dessa intervenção.

A um nível mais genérico, e operacional, a abordagem da revitalização confronta-se com a proliferação de noções potencialmente concorrentes: renovação, reabilitação, requalificação, etc., e poderemos organizar a literatura existente em torno de três posições distintas:

- Considerar a revitalização social enquanto dimensão contida em outras noções, nomeadamente na de planeamento urbano;

- Considerar a revitalização como conceito-mãe que alberga outras noções;

- Defender a natureza distinta das problemáticas sem que isso implique a recusa de eventuais relações substantivas entre os fenómenos que elas recobrem.

\section{Desafios e objectivos para um modelo operacional de revitalização}

Na discussão sobre uma intervenção urbana integrada e estratégica na Europa, podem destacar-se quatro grandes desafios e desígnios fundamentais da revitalização urbana:

1. aumentar a eficácia e a eficiência do sistema urbano, promovendo a coesão social e a competitividade territorial intra e intercidades - inserção das cidades nas redes transeuropeias, cooperação estratégica entre cidades a articulação entre a intervenção no espaço rural e urbano;

2. dinamizar a sociedade civil, promovendo o bem-estar urbano, a qualidade de vida dos cidadãos e a melhoria das empresas e do sistema económico;

3. promover uma intervenção urbana equilibrada e articulada, tendo em conta as dimensões ambientais, económicas, sociais e culturais;

4. contribuir para racionalização, modernização e responsansabilização da administração das áreas urbanas (central, local, instituições e cidadãos), propondo e implementando estratégias, mas também esperando valor e resultados.

Propõe-se que o conceito de Revitalização Urbana seja entendido sobretudo como uma estratégia e um processo, distinguindo-se da generalidade dos programas urbanísticos, de um modo geral sem transversalidade e integração nas suas linhas de actuação. Neste sentido, a revitalização urbana desenvolve estratégias e promove um processo com carácter inclusivo e integrador, capaz de provocar iniciativas, projectos e actuações - de carácter transversal e sectorial -, sendo um instrumento de gestão colectiva do território com capacidade para utilizar como recursos próprios, programas urbanos muito diferenciados, de cariz mais social, económico ou cultural.

Três objectivos fundamentais caracterizam o processo de revitalização urbana, enquanto planeamento estratégico transversal que interessa reter:

1. Capacidade de promover e manter a diversidade e a integração das esferas do desenvolvimento económico, social e do ambiente urbano, de modo a aumentar a qualidade de vida das populações;

2. Implementar projectos de desenvolvimento estratégicos, operadores de desenvolvimento e orientadores da mudança, antecipando problemas e direccionando soluções, procurando sinergias entre diferentes territórios, actividades económicas e populações;

3. Monitorizar os objectivos, considerando tanto os problemas como as oportunidades do território no mesmo processo de planeamento, decisão e intervenção estratégica, implicando os actores desde a fase de concepção da estratégia, da definição à execução de objectivos.

Algumas qualidades qualificam uma "área revitalizada" como a capacidade de gerar actividades, transacções e promover a diversidade:

- Actividades - sugere vitalidade, energia, animação, acontecimento num determinado contexto urbano, o que exige a presença de pessoas (a residir, a trabalhar, a passar), e viabilidade e sustentabilidade ao nível do que produz e como se mantém. Essa actividade corresponde a uma vitalidade económica (investimento na área, emprego, transacção de propriedades), social (uso do espaço público), social e cultural (eventos, espectáculos). 
- Transacções - trocas de nível económico (consumo, transacção de propriedades), social (relações, compromisso e participação), cultural (networks, trocas de informação e ideias).

- Diversidade - pode ser económica (de actividades, estabelecimentos, habitações), social (cidade facilitadora para a expressão de um individualismo criativo) e cultural (multi-identidades, cidade tolerante).

A revitalização, desenvolvida nesta perspectiva de processo e estratégia, procura articular territórios diferentes (rural/urbano, espaços transfronteiriços, relação lugar/nível regional e nacional...) e desenvolve uma política que cruza esferas de decisão de escala diferente, tanto vertical (de hierarquia diferente), como horizontalmente (multiplicidade de iniciativas sectoriais que podem ter influência no território).

\section{Dimensões do conceito de revitalização urbana}

As experiências das operações de intervenção urbana com desígnios semelhantes e a análise crítica dos Programas realizadas ao longo do documento permitem identificar seis dimensões integradas na definição actual do conceito de revitalização urbana.

\section{i) Integração sistémica: pensar global, agir local}

Nesse sentido, os programas de revitalização não esgotam as outras políticas territoriais com as quais devem estar relacionados e ser coerentes, nomeadamente:

a) ligação às políticas de solos - fomentar a existência de instrumentos ao dispor da Administração Pública para intervir de modo eficaz no funcionamento do mercado do solo, nomeadamente com a criação de bolsas de terrenos municipais que assegurem a existência de bens integrados no domínio municipal, disponíveis em valores suficientes para influenciar políticas de solos. Deste modo, os Municípios podem influenciar a actuação dos proprietários privados, nomeadamente no que respeita à disponibilização de solos para fins públicos, condição fundamental para envolver os parceiros privados na tarefa de revitalização urbana;

b) ligação à política nacional de habitação definir um conjunto alargado de medidas de regulação da oferta e procura habitacional e facilitando o acesso ao "direito à habitação" e ao "direito à cidade"; inverter a actual distribuição de apoios e incentivos à habitação, passando a privilegiar a reabilitação e o sector do arrendamento em detrimento do apoio à aquisição de cada própria; rever a lei do arrendamento, os incentivos fiscais à reabilitação de edifícios e o REGEU; penalizar os edifícios devolutos e degradados, assim como os terrenos expectantes, e facilitar à Administração Pública a sua disponibilização no mercado de habitação;

c) ligação aos vários instrumentos de planeamento a implementar ou implementados: - assegurar, ao nível dos planos municipais, a compatibilidade entre as opções de planeamento previstas no PDM e os programas de revitalização urbana, de nada adiantando uma intervenção isolada se a disciplina global do plano for num sentido de incremento desmesurado das áreas de construção com claro prejuízo para a qualidade de vida;

- diminuição das áreas classificadas como urbanas e urbanizáveis, e relocalização destas ao longo de eixos de territórios prioritários, articulando diferentes tecidos urbanos residenciais, secundários e terciários, dotados dos necessários equipamentos e infra-estruturas;

- miscigenização de actividades no espaço urbano, criando condições para que os espaços reabilitados sejam espaços "vivos", o que só se conseguirá se neles poderem ser desenvolvidas actividades que garantam a sua sustentabilidade económica;

- criação de ZUP (Zonas de Urbanização Prioritária), no sentido de estancar as urbanizações desgarradas e consequente interdição de loteamentos fora destas zonas. 
- reforço e requalificação dos centros urbanos tradicionais e implementação de novas centralidades como pólos de agregação de tecidos dispersos;

- criação/requalificação de espaços públicos enquadrados por tecidos residenciais.

\section{ii) A integração das dimensões físicas com as dimensões económicas, sociais, culturais e ambientais}

Uma base de reconhecimento comum sobre o conceito de revitalização urbana, refere-se a um modelo de intervenção que procura conciliar dimensões urbanísticas, arquitectónicas e patrimoniais, com objectivos económicos e sociais. Um progressivo reconhecimento de que o território são as pessoas fez acompanhar crescentemente os processo de reabilitação física com os de qualificação social. Os modelos de revitalização podem ser mais liberais ou mais "sociais", dependendo dos países e das opções políticas, mas definitivamente eles integram uma intervenção onde aos elementos físicos se juntaram as dimensões económicas de criação de empresas e de emprego, as dimensões sociais de requalificação humana e cultural das populações residentes.

Os espaços locais são encarados cada vez mais como espaços de oportunidade e os programas de revitalização como meios de inovação e experimentação social, ecológica, de participação, cooperação e gestão inovadoras.

\section{iii) Da reparação à prevenção}

Emerge a defesa crescente que a revitalização exige uma abordagem preventiva e não apenas reparadora dos problemas, activando programas e financiamentos para evitar a degradação física e social, agindo sobretudo ao nível local, adaptando-se às especificidades de cada área territorial e agindo a montante dos problemas (lutar contra os processos desvitalização). É assim que o discurso sobre os territórios "sensíveis", ou a tipologia já identificada que inclui territórios em formação ou em crescimento, são importantes para ensaiar formas de vitalização que antecipem e contrariem uma potencial degradação socio-urbanistica.

\section{iv) A intervenção dos actores privados: empresas, mas não só}

Há uma consciência recente de que a entrada dos interesses privados nas operações de revitalização é não apenas uma inevitabilidade, mas sobretudo uma potencialidade deste tipo de processos. Estas operações intervêm em territórios em larga medida de propriedade ou de uso de uma miríade alargada de actores privados - proprietários do solo, das casas, inquilinos, trabalhadores da área, etc., cuja adesão é indispensável. Mas esta presença, apesar de manifestar interesses potencialmente contraditórios, é também portadora de recursos e de culturas de formas de fazer multifacetadas.

O espaço não é propriedade do Estado, sendo embora regulado por ele, é produzido e apropriado por uma grande diversidade de actores sociais, e a capacidade de construir projectos colectivos e accionar sinergias que rentabilizem os recursos privados e harmonizem interesses contraditórios é também uma dimensão indispensável dos programas de reabilitação.

\section{v) Um espaço de gestão colectiva e de reforço do papel regulador do Estado}

Muitos dos participantes em processos de reabilitação urbana, dos mais variados matizes e temporalidades, chamam a atenção para a importância do processo de gestão colectiva destes espaços e, muito concretamente, para a necessidade imperiosa de envolvimento dos públicos-alvo.

A revitalização urbana pressupõe formas de fazer específicas, com inovação na criação de figuras de gestão para a transformação da forma de agir do Estado, que tem de actuar em sentidos pouco habituais: inserção temporal de medição dos processos urbanos, convergência de acções governamentais sectoriais, articulação de diferentes escalas de intervenção, combinação de contributos de actores sociais muito dissemelhantes (este ponto será desenvolvido na discussão dos modelos de gestão e participação no próximo ponto do relatório).

\section{vi) Sustentabilidade e inovação}

As dimensões atrás referidas como fazendo parte integrante do conceito de revitalização 
urbana, fazem inverter o olhar sobre os territórios a revitalizar. Não estamos já a olhar para territórios em declínio, mas para territórios cujo potencial de vitalização está emergente, esperando que um projecto colectivo suportado por actores variados (públicos, privados; nacionais, regionais ou locais) sob orientação pública, permita inovar ao nível das várias dimensões do desenvolvimento económico, social, cultural, arquitectónico e urbanístico, etc.

Um dos desafios dos programas de revitalização é a sua capacidade de inovação nas várias dimensões que movimenta e que pode ser desde ao nível da qualificação dos recursos humanos e da criação de emprego, até à inovação no desenvolvimento das energias renováveis ou na utilização das redes de alta velocidade para comunicação entre cidadãos. Aqui se introduz a dimensão experimental dos projectos de revitalização urbana a apoiar, que devem ser os que, partindo das potencialidades do local, lhe dão novas capacidades de desenvolvimento sustentado. Projectos experimentais, e sustentabilidade, são palavras-chave da nova geração de programas de revitalização urbana.

\section{Pressupostos para a intervenção}

Alguns pressupostos fundamentais podem ser referenciados neste momento.

O modelo de estratégia de revitalização proposto deve iniciar-se com a definição de um cenário de chegada. Este cenário de chegada é uma imagem do que se pretende que a área venha a ser após o processo de revitalização (definido para um horizonte alargado de 10 a 20 anos) e deve ser partilhado por todos os actores. Após esta formulação, deve ser desenhada uma estratégia para o alcançar a partir da situação actual e com os recursos (humanos, logísticos, temporais, financeiros, etc.) disponíveis. Esta estratégia define as metas gerais, baseadas em valores definidos e as abordagens e métodos a adoptar. Para cada meta devem ser definidos objectivos mensuráveis que quando alcançados darão resposta a essa mesma meta. Para facilitar o planeamento da acção, a prioridade dos objectivos deve também ser claramente definida.

Para uma reflexão e, posteriormente, uma acção, face a um “cenário de chegada” desejado, é importante que um processo de revitalização envol- va a comunidade (por um lado saber com quem é preciso aprender, por outro, saber com quem se quer caminhar), obrigando a planear, desenhar e implementar uma estratégia, a medir os resultados, e provocar uma disseminação e continuidade sistemática dessa intervenção. Só estes pressupostos tornam a revitalização um processo, uma estratégia e uma acção a médio e longo prazo.

Um outro pressuposto, já explorado anteriormente, está relacionado com a necessidade de desenvolver um processo de planeamento integrado, multidimensional, de modo a criar espaços para viver e trabalhar, assim como para o lazer ("live+work + play") utilizando e provocando ligações entre territórios, actividades e pessoas:

- desenvolvimento de estratégias participadas e integradas capazes de afectar as diversas dimensões que afectam cidade (meio físico e ambiental, problemas económicos, sociais);

- reabilitação física, social e cultural do território;

- promoção de uma economia social local ou urbana (coesão social, actores sociais) e do empreendedorismo; e

- implementação de planos de revitalização de médio e longo prazo, capazes de estimular e consolidar a intervenção.

Após a definição da estratégia, há dois processos que devem ocorrer simultaneamente: o planeamento da acção e a mobilização de recursos. O planeamento da acção deverá ter em conta a prioridade dos objectivos mensuráveis, as condições preexistentes, as abordagens e métodos escolhidos, as responsabilidades previstas dos actores e os recursos previsíveis. Como para as mesmas condições preexistentes, diferentes abordagens e métodos implicam diferentes recursos para atingir o mesmo objectivo, as actividades de planeamento da acção e de mobilização de recursos não só devem ser feitas simultaneamente, como devem dar um constante "feedback" uma à outra.

A estratégia deverá ter tradução num Plano de Revitalização. Este é um plano detalhado de como atingir os objectivos mensuráveis, com os recursos disponíveis num dado prazo de tempo. O seu grau de pormenor é muito superior ao da estratégia. O Plano de Revitalização deve ser estrategicamente fragmentado em peças opera- 


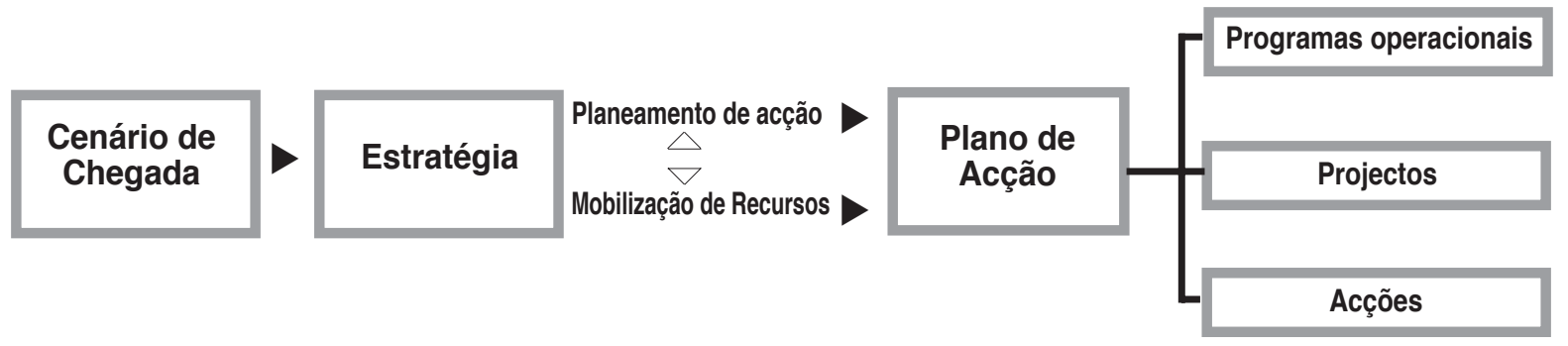

Figura 2 - Esquema de modelo de estratégia possível num processo de revitalização

cionais de menor escala (programas operacionais, projectos e acções) que darão resposta a objectivos específicos. Deve ainda activar diferentes modelos de participação, intervenção, monitorização e avaliação, de modo concreto, metodologicamente orientado e com objectivos e metas mensuráveis.

Alguns elementos base desse documento estratégico de revitalização (Plano) pressupõem:

- a relação entre a estratégia apresentada para a área e as estratégias existentes a outras escalas (cidade/região/país);

- os valores chave e princípios gerais a seguir por todos os objectivos e acções; metas gerais e objectivos mensuráveis coerentes entre si; relação existente entre as metas, os objectivos e o contexto;

- a definição de abordagens e métodos concertados para atingir os objectivos;

- a clarificação dos compromissos, responsabilidades e recursos que cada um dos actores acordou aplicar no processo de revitalização (em especial das autoridades públicas); e

- a descrição geral do processo a longo prazo; cronograma; programas operacionais, projectos e acções isoladas que no seu conjunto darão resposta integral aos objectivos.

\section{Territórios: \\ da classificação à elegibilidade}

\section{Pressupostos para a revitalização}

O enquadramento dos Territórios a Reabilitar/TRU, de acordo com a reflexão tida sobre o conceito de revitalização urbana (e antes de se materializar qualquer processo empírico de trabalho) baseia-se nas reflexões conceptuais efectuadas sobre áreas urbanas desvitalizadas e sobre os desafios que se colocam às cidades contemporâneas.

Nesse sentido, a construção de uma tipologia, quer ao nível da escala de análise, quer da escala de intervenção, tem em conta dois pressupostos fundamentais:

1. um, subjacente ao conceito de revitalização diz respeito à capacidade de definir territórios, cujas características (enquanto área desvitalizada ou a revitalizar) sejam suficientemente flexíveis, integradas e processuais;

2. outro, partindo das próprias exigências contratuais, diz respeito à capacidade de pensar a revitalização no plano nacional, não o reduzindo, como é frequente, à escala urbana-central, urbano-metropolitana ou peri-urbana.

Face à natureza de algumas decisões a tomar, identificam-se cinco grandes desafios para a construção de uma tipologia de Territórios de Revitalização Urbana:

1. A visão de uma estratégia nacional de inversão de processos de desvitalização urbana, válida para a "totalidade das localidades" (na perspectiva de que o programa deverá cobrir o território nacional), articulada com a necessidade de um programa experimental assente numa "selectividade territorial" (envolvendo apenas algumas localidades, seleccionados previamente com candidaturas decorrentes de processos de animação prévios, ou por iniciativa de candidaturas "espontâneas" com base em capacidade de iniciativa e organização preexistente), tendo em vista a promoção da inovação (aperfeiçoamento das formas de resposta nos diferentes domínios das políticas públicas que podem concorrer para a inversão de processos de desvitalização urbana). 
2. A necessidade de reflectir sobre áreas que estão em diferentes posições, em termos de uma classificação de um processo de desvitalização e declínio urbano. Podem-se identificar, a priori, 4 tipos de territórios:

I) "territórios em formação", espaços que não têm vitalidade urbana nem nunca tiveram,

II) "territórios em crescimento", espaços urbanos em que se identifica uma vitalidade crescente;

III) "territórios em perda", enquanto espaços onde a vitalidade urbana tem vindo a perder fulgor; ou

IV) "territórios desvitalizados", ou seja, espaços que não tendo vitalidade urbana já a tiveram no passado:
4. A complexidade, quando tem de se ter em conta áreas onde interagem diversos vectores dinâmicos, de múltiplas dimensões da desvitalização, que devem ser reconhecidos e medidos; e que, evidentemente, devem ser vistos de uma forma integrada, cujo entendimento e integração deve incluir a vertente da coesão social, da gestão urbana e dos processos de governação territorial.

5. A pertinência de uma discussão sobre escala de análise e de intervenção da revitalização face a diferentes dimensões, que se admitem como interdependentes mas que podem envolver exercícios diferenciados (exemplo, quando o local da concentração espacial de problemas não coincide com o local da sua causa próxima, ou quando

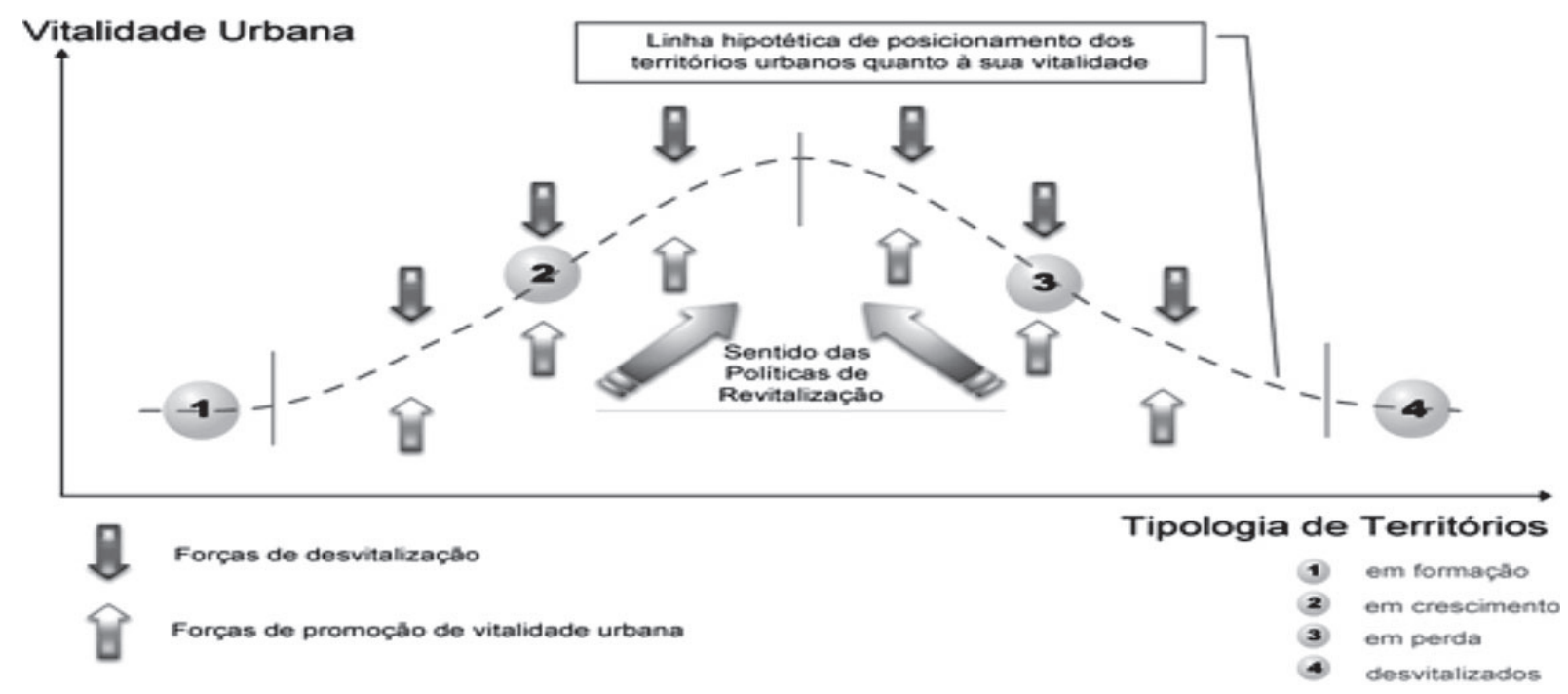

Figura 3 - Tipologia de territórios e processos de desvitalização/a revitalizar

3. A necessidade de integrar ou distinguir a perspectiva do lugar (acção local, em função de unidades territoriais constituídas com base nas fronteiras político-administrativas dos agentes-chave da intervenção (os Municípios, nos Concelhos) e a perspectiva sistémica (reflectindo, por exemplo, nas medidas tomadas a montante, sobre processos de impacto na desvitalização territorial), ou como classificar áreas a revitalizar tendo em conta, por um lado, a sua perspectiva de lugar, mas também considerando o seu contexto nacional (já que revitalizar tendo em conta a perspectiva local e nacional, não corresponde a escalas de intervenção "superiores" mas sim a problemáticas diferentes). uma decisão global se faz reflectir num processo local).

$\mathrm{O}$ quadro de incidência das intervenções em revitalização urbana, para todo o país, deve estar suportado por uma estratégia de âmbito nacional. Esta estratégia, vertida em documento aprovado superiormente, enquadra-se não só nos instrumentos já existentes ou em fase final de elaboração e aprovação [como os atrás referenciados Sistema Urbano Nacional definido pela DGOTDU (1996), o futuro Plano Nacional da Política de Ordenamento do Território (PNPOT), e os diversos PROT regionais], mas também em linhas conceptuais e programáticas sobre as novas e fundamentais visões e acções em sede de revitalização urbana para as cidades portuguesas. 
Em termos gerais, as áreas de revitalização urbana poderão ter uma maior incidência nas áreas metropolitanas de Lisboa e Porto, na medida em que as duas metrópoles integram de modo relativamente destacado - e distinto - não só um conjunto significativo de centros urbanos históricos, como também bairros de habitação social (duas figuras centrais de qualquer política de revitalização), para além de uma série de problemáticas prioritárias e bem contemporâneas para o desenvolvimento socioeconómico da sociedade portuguesa. No entanto, evidentemente que em múltiplas outras áreas urbanas do país (incluindo os arquipélagos dos Açores e da Madeira), as problemáticas em sede de TRU também se colocam com importante e elevada acuidade. Será necessário, por conseguinte, justificar as propostas de intervenção (e de perspectiva dinâmica), de acordo com cada contexto concreto de cidade, contexto este por sua vez enquadrável no de cada subsistema urbano, que se pretende equilibrado, sustentável, coeso e dinâmico.

A estabilização referencial das prioridades em termos de revitalização urbana, para além dos enquadramentos que encontra em sede de ordenamento do território (com base em documentos base referidos), articula-se também com dois pressupostos centrais para as novas realidades urbanas do Portugal do início do século XXI:

a. o pressuposto de que as grandes dinâmicas de mobilidade residencial de médio e largo espectro em Portugal, e que levaram a um crescimento populacional das cidades e metrópoles, apresentam desde meados dos anos 90 uma tendência para a estabilização. Tal facto é bastante visível ao nível das duas áreas metropolitanas, e na maioria das cidades médias (embora em alguns casos, como por exemplo nas áreas urbanas a norte da Área Metropolitana do Porto, se assista ainda a uma progressão demográfica relativa - mas com uma efectiva tendência para a estabilização) ${ }^{4}$; e

b. o pressuposto de que, perante esta estabi- lização demográfica (exceptuando o fenómeno da imigração), e perante o notável aumento, nas últimas duas décadas, do parque habitacional em praticamente todas as áreas urbanas ${ }^{5}$, que se deverá investir agora, decididamente, na qualificação dos espaços e das redes urbanas e das centralidades já existentes - muito nomeadamente em termos de uma valorização de cariz mais humano e qualitativo, e menos ligada a processos de simples dotação física, de pendor habitacional.

\section{Uma tipologia de territórios de revitalização urbana}

O "perfil tradicional" das áreas urbanas susceptíveis de políticas e programas em sede de Revitalização Urbana, toma em principal consideração as "áreas urbanas com sintomas claros de desvitalização", ou áreas em declínio.

Efectivamente, tal sentido das políticas de revitalização incide em territórios urbanos denominados de "desvitalizados" ou "em perda", e tem como objectivo voltar a dotá-los de uma vitalidade urbana que já terão possuído. Observando as políticas desenvolvidas na Europa e nos Estados Unidos verifica-se que muitos dos programas de revitalização se concentram em áreas urbanas degradadas, zonas de habitação social, e os indicadores de desvitalização, ou índices de perda são, de um modo generalizado, associados a fenómenos de exclusão social e económica da população residente e com menor peso, a decadência das actividades económicas, comerciais e de serviços.

Não obstante, a relevância da actuação neste tipo de áreas consideradas em declínio, a abrangência do perfil proposto para os territórios urbanos portugueses, com as suas diferentes tipologias (que detalharemos em seguida), não se deve cingir (embora deva privilegiar, dado um panorama constituinte de importantes carências e deficiências socioterritoriais) às áreas conside-

\footnotetext{
${ }^{4}$ Note-se que tal facto não considera - antes pelo contrário - que não haja importantes movimentações internas, em cada sistema urbano. O recente estudo da Câmara Municipal de Lisboa (2004a) mostra que, ao longo da década de 90, as dinâmicas de mudança residencial terão praticamente duplicado - dentro da AML, essencialmente.

5 Este processo foi essencialmente conduzido por via de uma cadeia de valor ligada à promoção do solo para fins urbanísticos, pouco regulada a nível global apesar dos instrumentos de gestão territorial. Esta situação tem reflexos, nomeadamente, em situações como a existência de um grande parque habitacional vago, em muitos dos casos com boas condições de habitabilidade.
} 
radas desvitalizadas, ou em processo de desvitalização. Efectivamente, podem também ser tomadas em consideração áreas com algum vigor urbano - áreas que, numa análise mais integrada (em termos, por exemplo, de prioridade estratégica perante o sistema urbano em que se inserem), sejam consideradas determinantes para o desenvolvimento de uma estratégia urbana de âmbito mais global.

Interessa ainda destacar, que processos pouco prudentes de procurar tornar uma área que se encontra desvitalizada, mais atractiva ao investimento, seja ao nível económico, como habitacional, social ou cultural (processos normalmente ligados a intervenções puramente físicas), pode tornar-se um factor de afastamento de importantes dinâmicas de vitalidade - tais como a não efectivação de uma ocupação habitacional (continuando os processos de despovoamento) ou o afastamento de vitais redes urbanas de proximidade e de identidade, tais como alguns tipos de actividades económicas (como o comércio de proximidade, por exemplo) ou múltiplas formas de manifestações sociais e culturais. É nestes paradoxos das intervenções que se deve questionar o "direito à cidade" e a equidade social da intervenção - promovendo verdadeiros tecidos urbanos (sociais, económicos, culturais e ambientais), com valores de cidadania, de ética e de estética, de proximidade e de mobilidade, de inclusão e de heterogeneidade (não meramente funcional, mas verdadeiramente social).

Foram considerados, face à natureza da intervenção urbana de revitalização e ao contexto nacional, 5 perfis territoriais de "estado da arte":

\section{A - Centros urbanos e núcleos históricos \\ B - Expansões periféricas ou peri-urbanas C - Áreas de oportunidade pontual ou estratégica \\ D - Espaços de reserva com potencialidade derivada \\ E - Espaços de relação e sinergia}

A análise de cada um desses perfis retoma os grandes objectivos, enunciados anteriormente, dos processos de revitalização urbana integrada:

- Promover a diversidade e a integração das esferas do desenvolvimento tanto do ambiente urbano, como económico e social no território, de modo a aumentar a qualidade de vida das populações;

- Implementar projectos de desenvolvimento estratégicos, isto é, procurar sinergias entre diferentes territórios, actividades económicas e populações, capazes de se tornarem operadores e orientadores de mudança, antecipando os problemas e direccionando as soluções;

- Monitorizar os objectivos, considerando tanto os problemas como as oportunidades do território no mesmo processo de planeamento e decisão estratégicos.

\section{A - Centros urbanos e núcleos históricos}

- Áreas degradadas ou com tendência para uma situação de desvitalidade urbana, obsolescência de uma grande parte do parque residencial ou ligação a áreas industriais ou portuárias decadentes;

- Áreas com processos de densificação e sobreocupação, ou abandono e deterioração;

- Áreas com concentração de classes mais desfavorecidas, despovoamento originado por diversas causas: redução do número de habitantes/fogo, degradação dos edifícios, número elevado de habitações devolutas, envelhecimento da população...;

- Áreas com subutilização das infra-estruturas e equipamentos instalados, resultante de um despovoamento (escolas a fechar, crise no comércio de bairro agravado este pela concorrência dos centros comerciais instalados na periferia, decréscimo do número de utentes dos transportes públicos, mesmo em Lisboa, apesar do aumento da rede do Metropolitano...).

Dos três grandes vectores globais de revitalização urbana, o vector mais prioritário para esta tipologia é o primeiro vector - a promoção da diversidade económica e social. Tal vector inclui os objectivos da complexidade, da multifuncionalidade, da proximidade e da mobilidade, à escala humana, perante os múltiplos elementos constituintes da vida urbana. No entanto, e precisamente no sentido da promoção da diversidade, será também vital o segundo vector - a implementação de projectos estratégicos, muito especialmente através das áreas mais avançadas de formação e cultura, do ambiente urbano e dos espaços públi- 
cos, da investigação e tecnologia, e da economia baseada no conhecimento. Este entendimento pressupõe o re-estabelecimento de centralidades dinâmicas e com identidade, quer a nível social, quer cultural e económico, perante os novos contextos de afirmação dos territórios.

\section{B - Expansões periféricas ou peri-urbana}

- Espaços complexos, com fraca qualidade da habitação e problemas derivados da grande heterogeneidade cultural em situação de pobreza, com reduzidas ofertas de emprego (favorecendo assim a função dormitório), e sofrendo de carências persistentes e, por vezes, em aumento: ao nível de equipamentos e infra-estruturas, sempre tardios e exigindo vultuosos investimentos públicos; ao nível também de transporte público, incentivado por isso o transporte privado nas deslocações pendulares; e no que toca a espaços públicos atractivos, apesar dos esforços das autarquias nos últimos anos;

- Processos de metropolização desorganizada, mudanças rápidas e não previstas nos mapas das acessibilidades e da centralidade;

- Constituídas por tecidos residenciais, ora fortemente concentrados, ora fragmentados;

- Pode incluir espaços de habitação social ou de origem ilegal (AUGI).

Dos três grandes vectores de revitalização urbana, o vector prioritário para esta tipologia é o segundo vector - a implementação de projectos estratégicos, muito especialmente através do fomento da qualidade de vida e da identidade social, e do combate aos fenómenos de exclusão social. No entanto, e tal como referido anteriormente, também nestas áreas se deverá potenciar a qualidade de vida pública, a diversidade, a heterogeneidade e a mobilidade á pequena escala - no âmbito dos projectos definidos como prioritários.

\section{C - Áreas de oportunidade pontual ou estratégica}

- Territórios vinculados a projectos de infra-estruturas, por exemplo, um aeroporto ou a construção de uma ponte;
- Espaços onde o desenvolvimento de projectos de larga escala (ex. projecto turístico, reconversão de uma área urbana) potencia o aparecimento de novas oportunidades com carácter pontual e fáceis de reconhecer no mercado;

- Espaços cujos investimentos induzem revalorizações rápidas no uso do solo (nem sempre positivas), mas também potencialidades que necessitam de um esforço público para as tornar visíveis a médio e longo prazo.

Dos três grandes vectores globais de revitalização urbana, o vector prioritário para esta tipologia é o segundo vector - a implementação de projectos estratégicos. No entanto, também os outros vectores (mesmo o primeiro) devem estar presentes - abdicando assim de se desenvolver projectos estratégicos desintegrados de um contexto urbano composto por elementos de diversidade funcional.

\section{D - Espaços de reserva com potencialidade derivada}

- Territórios inseridos ou próximos de áreas ecológicas ou agrícolas que se justificam pelo valor acrescentado que pode ser gerado através de um processos de revitalização;

- Áreas com novas regulações e normativas relativas, por exemplo, à gestão e ordenamento da paisagem, e que abrem possibilidades a projectos de revalorização do território natural, e sobretudo agrícola, vinculado ao património cultural e a políticas de sustentabilidade territorial.

Dos três grandes vectores globais de revitalização urbana, o vector prioritário para estes territórios é o primeiro - nestas áreas, a manutenção da diversidade é um objectivo que, quando atingido, possibilita e potencia a implementação de projectos estratégicos que podem gerar sinergias posteriores entre territórios, actividades e populações.

\section{E - Espaços de relação e sinergia}

- Relativos a novas oportunidades que emergem da mudança de valor de determinadas situações territoriais; 
- Espaços de grande permeabilidade económica, social e cultural como, por exemplo, os espaços fronteiriços.

Neste tipo de espaços, o vector prioritário é o segundo vector, pois a oportunidade deve ser vista como estratégica, oferecendo possibilidades de sinergias entre territórios, actividades e pessoas, o que poderia supor acordos entre Estados fronteiriços, de natureza regional, ou, pelo menos, supranacional.

\section{Conclusão}

As dinâmicas de reabilitação urbana estão hoje no centro do pensamento sobre a "questão habitacional": por um lado, porque as profundas transformações da sociedade actual e a transformação que trazem desactualizaram muitas áreas e funções urbanas e obrigam a repensar as novas áreas da cidade e, por outro lado, há um reconhecimento por parte dos analistas europeus que a maior parte dos problemas habitacionais estão resolvidos.

De facto, para a maioria dos países europeus, a necessidade quantitativa de alojamento é encarada como pertencendo ao passado e as políticas habitacionais são encaradas como respostas a grupos sociais específicos mais do que estratégias globais de acessibilidade ao alojamento. As preocupações orientam-se particularmente para a regeneração urbana e, dependendo da gravidade, para tentativas de estabilização dos actualmente voláteis mercados habitacionais privados.

Por sua vez, o debate académico centra-se nas problemáticas da diversidade, da escolha e da coexistência multicultural mais do que na linguagem da privação da pobreza urbana.

Estas transformações das dinâmicas demográficas e habitacionais são acompanhadas do recuo do Estado da maioria das políticas sociais nomeadamente das políticas de habitação e reabilitação urbana. Curiosamente, e infelizmente, a discussão sobre a reabilitação parece resumir-se à discussão sobre quem suporta os elevados encargos deste processo e, nesse sentido, a preocupação do Observatório da QCA em encomendar um estudo sobre a problemática é um bom sintoma sobre a preocupação com que a administração segue estes processos e uma afirmação da vontade pública em intervir. 


\section{Bibliografia}

ATKINSON, Rowland et Keith Kintrea (2001). "Disentangling Area Effects: Evidence from Deprived and non Deprived Neighbourhoods", Urban Studies, 38(12):2277-2298.

AUTHIER, Jean-Yves (2002). "Habiter son quartier et vivre en ville: les rapports résidentiels des habitants des centres ancien", Espaces et sociétés, 108/109(1/2):89-109.

BAILLY, Antoine (1984). "La géographie des représentations: espace perçus, espaces vécus", in Bailly, A., Les concepts de géographie humaine, Paris, Masson.

BAILLY, Antoine (1981). Géographie du bien-être, Paris, Presses Universitaires de France, 239 p.

BALL, Michael, Laurent Le Ny et Paul J. Maginn (2003). "Synergy in Urban Regeneration Partnership: Property Agents' Perspectives", Urban Studies, 40(11):2239-2253.

BARON, Gaëlle et Eric Monnier (2003). "Une approche pluraliste et participative: coproduire l'évaluation avec la société civile", Informations Sociales, no 110, «L'évaluation des politiques publiques», septembre-octobre, $7 \mathrm{p}$. http:// www.eureval-c 3 e.fr/publications/Evaluation $\% 20$ participative.pdf.

BACQUÉ, Marie-Hélène et al. (2003) Survol de quelques politiques de revitalisation urbaine, Institut National de Recherche Scientifique - Urbanisation, Culture et Société (INRS) (RAPPORT FINAL soumis á la Ville de Montréal, sur quelques politiques de revitalisation urbaine développées en Europe et au Etats-Unis http://www2.ville.montreal.qc.ca/plan-urbanisme/pdf/connexes/etude_revitalisation_urbaine.pdf)

BALSAS, Carlos José Lopes, Urbanismo Comercial em Portugal e a Revitalização do Centro das Cidades, 1999, GEPE, Lisboa

BAUER, Raymond A. (1966). Social Indicators, Cambridge, MIT Press, 357 pp.

BURCHELL, Robert and others, The Costs of Sprawl - Revisited, 1998, Washington D.C.: National Academy Press, Transportation Cooperative Research Program Report.

BAUM, Howell S. (2001). "How Should We Evaluate Community Initiatives", Journal of the American Planning Association, 67(2):147-158.

BERNARD, Paul, Michel Bernier, Johanne Boisjoly et JeanMichel Cousineau (2002). Comment mesurer le développement social?, rapport de l'équipe CQRS sur les indicateurs sociaux synthétiques, novembre, Québec, Conseil Québécois de la Recherche Sociale, 217 pp.

BRADFORD, Neil (2003). Cities and Communities that Work: Innovative Practices, Enabling Policies, Ottawa, Réseaux canadiens de recherche sur les politiques publiques, Discussion Paper F|32, juin, 96 p. http://www.cprn.com/en/ doc.cfm? doc $=318$

BUCK, Nick (2001). "Identifying Neighbourhood Effects on Social Exclusion", Urban studies, 38(1):2251-2275.

C.A.C. INTERNATIONAL (2003). Preliminary Assessment of the Pan-Canadian Learning Community - "Vibrant Communities", préparé pour le Caledon Institute of Social
Policy et Tamarack - An Institute for Community Engagement, Montréal, C.A.C. International, 33 pp.

http://www.vibrantcommunities.ca/downloads/f2f2003/ prelim_assess_pclc_may2003.pdf

CARLEY, M. (1990) Housing and Neighbourhood Renewal: Britain's New Urban.

CALEDON INSTITUTE OF SOCIAL POLICY (s.d.). Workshop Evaluation: Evaluating Strategic Interventions: Progress and Challenges in Vibrant Communities, Ottawa, l'Institut, 3 pp. http://www.vibrantcommunities.ca/downloads/f2f2003/ workshop_eval_notes.pdf

CAMERON, Stuart (2003). "Gentrification, Housing Redifferentiation and Urban Regeneration, "Going for Growth" in Newcastle upon Tyne», Urban Studies, 40(12):2367-2382.

COMMISSION EUROPÉENNE (1999?). Nouvelle période de programmation 2000-2006: documents de travail méthodologiques, document de travail no 3 , Indicateurs pour le suivi et l'évaluation: une méthodologie indicative, Bruxelles, La Commission, Direction générale XVI, Politique régionale et cohésion, coordination et évaluation des interventions http://europa.eu.int/comm/regional_policy/sources/docoffic/ working/doc/indic_fr.pdf

CML, Diagnóstico Sócio-Urbanístico da Cidade de Lisboa. Uma perspectiva censitária (2001), 2004a.

CML, Desenvolvimento Económico e Competitividade Urbana de Lisboa, 2004b.

COMMISSION EUROPÉENNE (1999?). Nouvelle période de programmation 2000-2006: documents de travail méthodologiques, document de travail no 3 , Indicateurs pour le suivi et l'évaluation: une méthodologie indicative, Bruxelles, La Commission, Direction générale XVI, Politique régionale et cohésion, coordination et évaluation des interventions http://europa.eu.int/comm/regional_policy/sources/docoffic/ working/doc/indic_fr.pdf

DGOTDU, Vocabulário do Ordenamento Urbano, 2000, Lisboa.

DGOTDU, Sistema Urbano Nacional: Cidades Médias e Dinâmicas Territoriais (3 volumes), 1996, Lisboa.

Direcção-Geral do Desenvolvimento Regional, "Programas Urban e Reabilitação Urbana- Revitalização de Áreas Urbanas em Crise", 1997, DGDR, Lisboa.

Direcção-Geral do Desenvolvimento Regional, "2 $\int$ Encontro dos Programas Urban e Reabilitação Urbana", 1998, DGDR, Lisboa.

FITZPATRICK, Dan and Murphey, Marlene. 2001/2002 RDA Project Goals, May 2001.

GRUEN, Victor. The Heart of Our Cities. New York: Simon and Shuster, 1964.

HORTAS, Maria João, "Pedestrianization, Retail and Urban Revitalisation: The case of Lisbon" in Estudos para o Planeamento Regional e Urbano (52), 2000, Centro de Estudos Geográficos da Universidade de Lisboa, Lisboa. 
INE, Estudo sobre o Poder de Compra Concelhio 2004, 2004.

INE, Sistema Urbano: Áreas de Influência e Marginalidade Funcional, 2004

INE, Indicadores Urbanos do Continente, 1999.

INE, Recenseamentos Gerais da População e da Habitação, Dados Comparativos 1991-2001, CD-ROM.

KAMAL-CHAOUI, L. (2001) Urban Distressed Areas and Cities Competitiveness. UNHABITAT: International Forum on Urban Poverty (IFUP). Marrakech, Morocco. http:// www.unhabitat.org/programmes/ifup/conf/w5.htm

O'HARA, Sabine U., “Urban Development Revisted: the Role of Neighborhood Needs and Local Participation in Urban Revitalization", in Review of Social Economy, 2001-2003, vol.59, pp. 23-40.

PEREIRA, Luz Valente, Metodologia de Planeamento de Reabilitação de Áreas Urbanas, 1996, LNEC, Lisboa.

RANDOLPH, B. and Judd, B. (1999) Social Exclusion, Neighbourhood Renewal and Large Public Housing Estates, Paper presented to the 1999 National Social Policy Conference, University of New South Wales, Sydney.

ROGERS TYM and PARTNERS et University of the West of England (1999). Local Evaluation for Regeneration Partnerships, préparé pour le Department of Environment, Transport and Regions.

(DETR), Londres, UK, Office of the Deputy Prime Minister, $27 \mathrm{pp}$.

http://www.odpm.gov.uk/stellent/groups/odpm urbanpolicy/ documents/pdf/odpm_urbpol_pdf_608055.pd
SCHIEFLOE, Per Morten (1990). "Networks in Urban Neighbourhoods: Lost, Saved or Liberated Communities?", Scandinavian Housing and Planning Research, 7(1).

SÁ MARQUES, Teresa, Portugal na transição do século. Retratos e dinâmicas territoriais. Edições Afrontamento. 2004.

SEIDMAN, Karl F., "Revitalizing inner-city neighborhoods on the United States", in International Journal of Urban and Regional Research, 2001-2003, vol. 25, pp. 185-190.

UNITED NATIONS. Department for Policy Coordination and Sustainable Development (1996). Indicators of Sustainable Development: Framework and Methodologies, New York, United Nations, 428 p. (Cat.No. E.96.II.A.16).

UNITED KINGDOM. Office of the Deputy Prime Minister. Social Exclusion Unit (2003a). A Better Education for Children in Care, Londres, UK, Cabinet Office, The Social Exclusion Unit, 110 pp.

VAN BECKHOVEN, Ellen et Ronald Van Kempen (2003) "Social Effects of Urban Restructuring: A Case Study in Amsterdam and Utrecht, The Netherlands". Housing Studies 18(6): 853-875.

VAN CRIEKINGEN, Mathieu et Jean-Michel Decroly (2003). "Revisiting the Diversity of Gentrification: Neighbourhood Renewal Processes Brussels and Montreal", Urban Studies, 40

VAN DER BERG, Leo, Jan Van der Meer et Peter M. J. Pol (2001). Social Challenges and Organising Capacity in Cities. Experiences in Eight European Cities, Rotterdam, Erasmus University, European.

VILLE DE MONTRÉAL (2003). Projet pilote de revitalisation urbaine intégrée. Démarche d'évaluation et de développement d'indicateurs de développement social, octobre. 